\title{
The Effect of Acetohydroxamic Acid on Stainless Steel
}

\section{Corrosion in Nitric Acid}

\author{
Richard J. Wilbraham, Colin Boxall
}

The LRF Centre for Nuclear Engineering, Engineering Department, Lancaster University, Bailrigg, Lancashire, LA1 4YW, United Kingdom

r.wilbraham@lancaster.ac.uk, c.boxall@lancaster.ac.uk

\section{RECEIVED DATE}

*To whom all correspondence should be sent. E-mail: c.boxall@lancaster.ac.uk. Tel.: +44 1524593109 The LRF Centre for Nuclear Engineering, Engineering Department, Lancaster University, UK.

ABSTRACT: We present the first study of the effect of acetohydroxamic acid (AHA) on the corrosion behaviour of stainless steels. Particularly, studies have been performed using steels and physicochemical conditions equivalent to those proposed for use in advanced nuclear reprocessing platforms. In these, AHA has been shown to have little effect on either steel passivation or reductive dissolution of both SS304L and SS316L. However, under transpassive dissolution conditions, AHA while in part electrochemically oxidised to acetic acid and nitroxyl/hydroxylamine, also complexes with $\mathrm{Fe}^{3+}$, inhibiting secondary passivation and driving transpassive dissolution of both steels.

KEYWORDS: Corrosion, Acetohydroxamic acid, Stainless Steel 


\section{Introduction}

The PUREX (Plutonium and URanium EXtraction) separation process is used worldwide to recover uranium and plutonium from dissolved spent nuclear fuel (SNF). It is based on the selective liquid/liquid extraction and separation of uranium and plutonium from nitric acid solutions of dissolved SNF by use of a tri-n-butylphosphate (TBP) extractant in odourless kerosene (OK) [1].

As part of an Advanced PUREX process (Adv-PUREX), the use of acetohydroxamic acid (AHA) has been proposed as a means to hold back $\mathrm{Pu}$ and $\mathrm{Np}$ in the aqueous phase, thus allowing $\mathrm{U}(\mathrm{VI})$ to be extracted into the TBP without $\mathrm{Pu} / \mathrm{Np}$ contamination [2-6]. This has led to the development of a variety of advanced fuel cycle concepts that incorporate AHA, such as URanium EXtraction Plus (UREX+) [7,8] and Grouped ActiNide Extraction (GANEX) [9,10], which do not extract pure plutonium but rather a mix of $\mathrm{Pu}, \mathrm{Am}$ and $\mathrm{Np}$, providing a non-proliferation advantage over the traditional PUREX process [11].

Importantly, with regards to safety, little is known about the influence of AHA on the corrosion behaviour of the steels that typically make up process pipework, tanks and centrifugal contactors in each extraction step. It has been reported that di- and long chain mono-hydroxamic acids at concentrations $\leq 5$ mmol $\mathrm{dm}^{-3}$ may act as corrosion inhibitors through self-assembled monolayer formation [12,13]. However, hydroxamic acids have seen no study at concentrations higher than $0.1 \mathrm{~mol} \mathrm{dm}^{-3}$, typical of those suggested in UREX, GANEX and Adv-PUREX flowsheets. Further, hydroxamic acids themselves, while known to have high affinities for e.g. $\mathrm{Fe}^{3+}$ (present in all steels) [14,15], have not specifically been studied in a corrosion context.

Thus, here we present preliminary electrochemical corrosion studies that have been performed on the nuclear process steels, 304L and 316L stainless (SS) in the presence of AHA concentrations up to 0.5 mol dm${ }^{-3}$ in the presence of $\mathrm{HNO}_{3}$ concentrations typical of those expected in the aqueous phase of a UREX+/GANEX/Adv-PUREX process. 


\section{Experimental Section}

\subsection{Materials}

All chemicals were of AnalaR grade or better and supplied by Sigma Aldrich (Gillingham, Dorset, UK). All $\mathrm{H}_{2} \mathrm{O}$ used was Ultrapure from a Direct-Q 3 UV Millipore water purification system (Millipore, Watford, UK) to a resistivity of $18.2 \mathrm{M} \Omega . \mathrm{cm}$.

\subsection{AHA Preparation}

A $20 \mathrm{ml}$ stock solution of $0.54 \mathrm{~mol} \mathrm{dm}^{-3}$ AHA was prepared in deionised $\mathrm{H}_{2} \mathrm{O}$ and used for both LSV and EQCM studies. The stock solution was kept refrigerated up to a maximum of five days and colourmetrically checked daily for AHA degradation using UV-vis spectrophotometry [14].

\subsection{Linear Sweep Voltammetry (LSV) Studies of SS304L and SS316L in the Presence of AHA}

All LSV experiments were conducted in a small volume $(200 \mu \mathrm{l})$ electrochemical cell in order to achieve high AHA concentrations while minimizing teratogenic risk [16]. LSV measurements were performed using a PGSTAT120N potentiostat (Metrohm Autolab B.V., Utrecht). Working electrodes were constructed using 1 mm diameter SS316L (wt.\%: C-0.015\%, Si-0.38\%, Mn-1.5\%, P-0.035\%, S0.002\%, Cr-17.0\%, Mo-2.5\%, Ni-10.0\% and the remainder Fe) and SS304L (wt.\%: C-0.03\%, Si-0.75\%, Mn-2.0\%, P-0.04\%, S-0.015\%, Cr-18.0\%, Ni-10.0\% and the remainder Fe) wire (Advent, Oxford, UK) in glass Pasteur pipettes, backfilled with epoxy resin and polished using decreasing SiC paper grades and 6, 3 and $1 \mu \mathrm{m}$ diamond polishing pastes. To complete the three electrode cell a Ag/AgCl reference (RE-5B, Bioanalytical Systems Inc., USA) and coiled platinum wire counter electrodes were inserted via a simple PTFE manifold.

Aliquots of the AHA stock were taken and diluted to the desired concentration before being acidified using concentrated $\mathrm{HNO}_{3}$ to a concentration of $1.13 \mathrm{~mol} \mathrm{dm}{ }^{-3}$ (5\% wt.). Current measurements were then recorded from 0.5 to $1.5 \mathrm{~V}$ at a scan rate of $10 \mathrm{mV} \mathrm{s}^{-1}$.

\subsection{Electrochemical Quartz Crystal Microbalance (EQCM) Studies of SS2343 in the Presence}

\section{of AHA}


EQCM experiments were conducted using a RQCM frequency counter (Inficon Ltd, Blackburn UK) and Q-sense open module (Biolin Scientific, Cheshire, UK) connected to a PGSTAT20 potentiostat (Metrohm Autolab B.V.). QCM piezoelectrodes were comprised of polished SS2343 (wt.\%: C-0.020\%, Si-0.38\%, Mn-1.5\%, P-0.041\%, S-0.025\%, Cr-16.5\%, Mo-2.5\%, Ni-10.5\% and the remainder Fe) and were supplied from Biolin Scientific. SS2343 is a compositional analogue of SS316L with almost identical electrochemical/potentiodynamic properties as SS316L [17].

QCM crystal substrates were AT-cut quartz with a nominal resonant frequency of $5 \mathrm{MHz}$. Piezoelectrodes were created using physical vapour deposition (PVD) of SS2343 onto a thin Ti/Au adhesion layer (front and rear). The thickness of the steel layer is $100 \mathrm{~nm}$ with a surface roughness of $1.4 \mathrm{~nm}( \pm 0.2 \mathrm{~nm})$ with little reduction in the fundamental frequency of $5 \mathrm{MHz}$. Frequency change to mass conversion was conducted assuming the applicability of the Sauerbrey equation [18] and a conversion factor of $0.0557 \mathrm{~Hz} / \mathrm{ng} / \mathrm{cm}^{2}$. This conversion factor was determined by the standard $\mathrm{Cu}$ deposition and stripping method $[19,20]$.

Experimentally, $2 \mathrm{ml}$ aliquots of the AHA solution were prepared as above. Simultaneous LSVs and voltamassograms were then recorded from 0.5 to $1.5 \mathrm{~V}$ at a scan rate of $10 \mathrm{mV} \mathrm{s}^{-1}$ using a platinum wire counter and Ag/AgCl reference electrode. Ex situ SEM images and roughness measurements using a Phenom desktop SEM (Phenom-world, Eindhoven) were taken before and after each electrochemical experiment to assess any associated changes in surface morphology. 


\section{Results and Discussion}

\subsection{Linear Sweep Voltammetry Studies of SS304L and SS316L in the Presence of AHA}

Linear sweep voltammograms and associated polarisation curves for SS304L and SS316L in AHA concentrations from 0.1-0.5 mol dm${ }^{-3}$ are shown in Fig 1.

Considering first the polarisation curves of Fig. $1 \mathrm{~b}$ and $1 \mathrm{~d}$, it can be that there is little change in $\mathrm{E}_{\text {corr }}$, $\mathrm{i}_{\text {corr }}$ and the range of passivity with increasing AHA concentration for both steels. The primary difference in the polarisation curves is an increase in transpassive current with increasing AHA concentration.

From the LSVs of Fig. 1a and 1c, it can be seen that AHA at concentrations from 0.1-0.5 mol $\mathrm{dm}^{-3}$ significantly increases the oxidation current in the transpassive region for both steels. A larger transpassive current is observed for SS316L compared to SS304L, presumably due to the decreased silica content in SS316L which protects against intergranular corrosion in oxidative acidic environments [21,22]. However, it is interesting to note that while secondary passivation is inhibited by AHA for SS304L at potentials $>\sim 1.2 \mathrm{~V}$, it appears to be maintained in SS316L samples.

A large increase in transpassive current would initially suggest that extremely rapid dissolution of the steel is occurring. However, visual inspection of both steel wire electrodes revealed no significant changes in surface morphology. Electrochemical studies of AHA oxidation using platinum electrodes $[23,24]$ have reported irreversible oxidation of a range of mono-, di- and tri-hydroxamic acids at 0.555 V vs. Ag/AgCl at pH $4(0.791 \mathrm{~V}$ at $\mathrm{pH}$ 0). Thus, this suggests that the transpassive currents of Fig. 1 are not purely due to transpassive dissolution but are rather a convolution of both AHA oxidation and steel dissolution.

\subsection{Microgravimetric Studies of SS2343 Dissolution in the Presence of AHA}

In order to deconvolute steel dissolution from AHA oxidation, simultaneous linear sweep voltammograms and voltamassograms of SS2343 (as a compositional analogue of SS316L) piezoelectrodes were recorded using the EQCM. Prior to scanning, the open circuit potential of SS2343 
was recorded for both $5 \%$ wt. $\mathrm{HNO}_{3}$ alone and in the presence of $0.5 \mathrm{~mol} \mathrm{dm}{ }^{-3}$ AHA and found to be 0.5 and 0.55 V respectively. Simultaneous linear sweep voltammograms and voltamassograms of SS2343 are shown in Fig.2a and Fig 2b respectively.

Considering first the data for $5 \%$ wt. $\mathrm{HNO}_{3}$ only, it can be seen that the current trace does not mirror the mass trace. Specifically, the voltamassogram of Fig. 2b suggests that there is no secondary passivation in the transpassive region, while the LSV data of Fig. 2a shows a levelling off of the current typical of passivation. To analyse this region in more detail the mass change was differentiated with respect to voltage. The resulting $\mathrm{d} \Delta \mathrm{m} / \mathrm{dV}$ vs. potential plot (not shown) reveals a plateau at $\mathrm{E}>1.1 \mathrm{~V}$, i.e. mass loss continues at a constant rate in this potential region despite the presence of secondary passivation, suggesting that the secondary passive layer is porous in character. Such a layer has been previously observed on 304 stainless steels in sulphuric acid solutions by Song et al. [25,26]. They determined that this layer is predominantly non-stoichiometric $\mathrm{Fe}_{2} \mathrm{O}_{3}, \mathrm{Cr}_{2} \mathrm{O}_{3}$ and $\mathrm{NiO}$ with some other constituents such as stoichiometric $\mathrm{Fe}_{3} \mathrm{O}_{4}$ and metal hydroxides. Importantly, Song et al. also find that the Cr content of this layer is significantly lower than that found in the passivating film produced in the primary passivation region of SS304. The comparative lack of $\mathrm{Cr}$ in this secondary passivation layer results in a low breakdown potential, explaining the porous character identified from our results above.

Based on the above, the LSV for $5 \%$ wt. $\mathrm{HNO}_{3}$ at potentials $>0.7 \mathrm{~V}$ can be divided into the following regions as indicated on Fig. 2: (i) Initial onset of transpassivity as $\mathrm{Cr}^{3+}$ is converted to higher valency $\mathrm{Cr}^{6+}$ in the passive layer $[27,28]$. (ii) Complete breakdown of the $\mathrm{Cr}$ passive film and uninhibited dissolution of underlying iron as $\mathrm{Fe}^{3+}$. (iii) Secondary passivation, initiated through $\mathrm{O}^{2-}$ anions and $\mathrm{Fe}^{3+} / \mathrm{Cr}^{3+} / \mathrm{Ni}^{2+}$ cations meeting at a suitable lattice site [25]. (iv) Oxygen evolution [29]. The observed $\mathrm{O}_{2}$ evolution current is low in region (iv), with only a slight increase in current apparent. Presumably this last observation is due to the secondary passivation layer restricting solution access to the underlying metal electrode, its porosity notwithstanding.

Considering now the voltamassogram and LSV data for SS2343 in 5\% wt. $\mathrm{HNO}_{3}$ with 0.5 mol dm $\mathrm{dm}^{-3}$ 
AHA, it can be seen from Fig. 2a that in the presence of AHA there is a larger increase in current with potential at the onset of transpassivity (region (i)) than in the absence of AHA. However, comparison with the simultaneously recorded voltamassogram, Fig 2b, reveals that there is no change in the rate of mass loss from the electrode surface. As discussed above, the larger currents seen in Fig. 2a in the presence of AHA compared to those recorded in its absence are likely associated with AHA oxidation to nitroxyl/hydroxylamine and acetic acid [23,24,30,31]. With regards to Fig. 2b, the electrochemical oxidation of AHA has been previously suggested by Shackleford to occur in solution rather than via a surface adsorbed species [32], explaining why there is no observed difference mass change recorded in this region compared to that seen in $\mathrm{HNO}_{3}$ only.

Region (iii) shows the greatest difference between experiments conducted in the presence and absence of AHA. From the voltamassogram and LSV of Fig. 2, AHA appears to inhibit secondary passivation at $\mathrm{E}>1.1 \mathrm{~V}$, most likely by formation of well-known $\mathrm{Fe}^{3+}$-AHA complexes [14] from oxidatively generated free $\mathrm{Fe}^{3+}$ at the electrode surface, so interrupting secondary passivation formation and driving transpassive dissolution. Further, dissolution of the steel continues up to $1.5 \mathrm{~V}$, Fig. 2b, the marked change in current at $\sim 1.3 \mathrm{~V}$ in Fig. 2a being due to the onset of $\mathrm{O}_{2}$ evolution at the exposed metal electrode.

SEM images and associated surface roughness values of the SS2343 coated piezoelectrodes employed in Fig. 2 are shown in Fig. 3. Fig.3c reveals no observable changes in morphology upon cycling in the presence of AHA compared to its absence, Fig. 3b, or even no cycling at all, Fig. 3a. However, comparison of concomitant roughness values for Figs. Зa-c shows a decrease in average surface roughness $\left(\mathrm{R}_{\mathrm{a}}\right)$ and maximum surface roughness $\left(\mathrm{R}_{\mathrm{z}}\right)$ in the presence of AHA compared to uncycled piezoelectrodes and those cycled in $\mathrm{HNO}_{3}$ only, suggesting any corrosive action is uniform in nature and akin to electropolishing of the surface (i.e. removing any surface deposits).

Cycling in AHA also produced a visible pink solution colouration at the piezoelectrode surface. To determine the origin of this colouration, the working solution was sampled after electrochemical 
scanning, diluted and analysed using UV-vis spectrophotometry (not shown). Comparison with absorbance peak values for acetohydroxamatoiron(III) complexes reported by Andrieux et al. [14], revealed the presence of the monoacetohydroxamatoiron(III) complex suggesting that electrogenerated $\mathrm{Fe}(\mathrm{III})$ is sequestered from the electrode surface in this form.

It is important to note that when iron is freely dissolving with no secondary passivation, region (ii), the rate of mass loss in the presence of AHA is the same as in its absence. Thus, the corrosion accelerating behaviour of AHA is limited to situations where solution redox potential $>+1.1 \mathrm{~V}$. However, few studies exist on the solution potential that obtains in aqueous reprocessing streams. From the scant literature that does exist, the solution potential may potentially be up to $1.15 \mathrm{~V}$, depending on actinide species present, acidity and temperature [33-35]. From our own studies on non-active thermodynamic simulants for $\mathrm{Pu}(\mathrm{IV})$ containing systems, potentials as high as $1.1 \mathrm{~V}$ can be observed at simulant metal ion concentrations as low as $0.1 \mathrm{mmol} \mathrm{dm}^{-3}$ [36], a value that would only be expected to be higher at concentrations more typical of reprocessing streams (especially, as may occur in the near future, during the recycle of higher burnup fuels) and under certain maloperation conditions such as low $\mathrm{pH}$ excursions or high temperature. According to Fig. 2b this would place the solution potential in an area where AHA would significantly increase the rate of SS316L dissolution, suggesting that the use of higher grade steels (e.g. SS310) or transpassive corrosion inhibitors may be necessary if AHA based reprocessing flow sheets are adopted for full scale nuclear fuel recycling in the future. 


\section{Conclusion}

The electrochemical corrosion behaviour of acetohydroxamic acid (AHA) on the nuclear process steels SS304L and SS316L has been investigated using linear sweep voltammetry and electrochemical microgravimetry.

AHA has been shown to have little effect on either steel passivation or dissolution at applied potentials $<1.1 \mathrm{~V}$. However, at transpassive dissolution potentials $>1.1 \mathrm{~V}$, AHA complexes with $\mathrm{Fe}^{3+}$, inhibiting secondary passivation and driving transpassive dissolution of both SS304L and SS316L.

Such an observation may have important implications for next generation nuclear fuel reprocessing flow sheets (GANEX, UREX, Adv-PUREX) that may use AHA, as potentials $>1.1 \mathrm{~V}$ could be accessible at higher actinide loadings or under maloperation conditions. As such additional safety measures may be required if AHA based reprocessing flow sheets are adopted for full scale nuclear fuel recycling in the future.

Acknowledgement. RJW and CB are supported by The Lloyd's Register Foundation (LRF). The Lloyd's Register Foundation supports the advancement of engineering-related education, and funds research and development that enhances safety of life at sea, on land and in the air.

\section{References and Notes}

[1] J.M. McKibben, Radiochim. Acta, 36 (1984) 3-15.

[2] P. Tkac, M. Precek, and A. Paulenova, Inorg. Chem., 48 (2009) 11935-11944.

[3] R.J. Taylor, I. May, A.L. Wallwork, I.S. Denniss, N.J. Hill, B.Ya. Galkin, B.Y. Zilberman, and Yu.S. Fedorov, J. Alloys Compd., 271-273 (1998) 534-537.

[4] M.J. Carrott, O.D. Fox, G. Le Gurun, C.J. Jones, C. Mason, R.J. Taylor, F.P.L. Andrieux, 
and C. Boxall, Radiochim. Acta, 96 (2008) 333-343.

[5] B.S. Matteson, M. Precek, and A. Paulenova, A study of the kinetics of the reduction of neptunium(VI) by acetohydroxamic acid in perchloric acid, Actinides 2009 IOP Conference Series: Materials Science and Engineering. IOP Publishing, 2010, pp. 1-9.

[6] F.P.L. Andrieux, C. Boxall, I. May, and R.J. Taylor, J. Solution Chem., 37 (2008) 215232.

[7] L. Nunez and G.F. Vandegrift, Evaluation of hydroxamic acid in uranium extraction process: Literature review. ANL-00/35, 1-17. 2001. Argonne, USA, Argonne National Laboratory.

[8] D. Olander, J. Nucl. Mater., 389 (2009) 1-22.

[9] K. Bell, C. Carpentier, M.J. Carrott, A. Geist, C. Gregson, X. Heres, D. Magnusson, R. Malmbeck, F. McLachlan, G. Modolo, U. Mullich, M. Sypula, R.J. Taylor, and A. Wilden, Proc. Chem., 7 (2012) 392-397.

[10] M.J. Carrott, K. Bell, J. Brown, A. Geist, C. Gregson, X. Heres, C. Maher, R. Malmbeck, C. Mason, G. Modolo, U. Mullich, M. Sarsfield, A. Wilden, and R.J. Taylor, Solvent Extr. Ion Exch., 32 (2014) 447-467.

[11] C.G. Bathke, B.B. Ebbinghaus, B.A. Collins, B.W. Sleaford, K.R. Hase, M. Robel, R.K. Wallace, K.S. Bradley, J.R. Ireland, G.D. Jarvinen, M.W. Johnson, A.W. Prichard, and B.W. Smith, Nucl. Technol., 179 (2012) 5-30.

[12] A. Alagta, I. Felhosi, I. Bertoti, and E. Kalman, Corros. Sci., 50 (2008) 1644-1649.

[13] A. Alagta, Investigation of carbon steel corrosion inhibition by hydroxamic acids. 1-92. 2009. Budapest University of Technology and Economics. 17-12-2009. http://hdl.handle.net/10890/842 
[14] F.P.L. Andrieux, C. Boxall, and R.J. Taylor, J. Solution Chem., 37 (2008) 1511-1527.

[15] F.P.L. Andrieux, C. Boxall, and R.J. Taylor, J. Solution Chem., 36 (2007) 1201-1217.

[16] N.C. Bailie, C.A. Osborne, J.R. Leininger, T.F. Fletcher, S.D. Johnston, P.N. Ogburn, and D.P. Griffith, Am. J. Vet. Res., 47 (1986) 2604-2611.

[17] C. Donik, I. Paulin, and M. Jenko, Mater. Tehnol., 44 (2010) 67-72.

[18] G. Sauerbrey, Z. Phys., 155 (1959) 206-222.

[19] C. Gabrielli, M. Keddam, and R. Torresi, J. Electrochem. Soc., 139 (1991) 2657-2660.

[20] G.L. Borges, K.K. Kanazawa, J.G. Gordon, K. Ashley, and J. Richer, J. Electroanal. Chem., 364 (1994) 281-284.

[21] P. Fauvet, F. Balbaud, R. Robin, Q.T. Tran, A. Mugnier, and D. Espinoux, J. Nucl. Mater., 375 (2008) 52-64.

[22] J.S. Armijo, Corrosion, 24 (1968) 24-30.

[23] J.A. Amberson and G. Svehla, Anal. Proc. (London), 23 (1986) 443-446.

[24] D. Arrigan, B. Deasy, J.D. Glennon, B. Johnston, and G. Svehla, Analyst, 118 (1993) 355-359.

[25] G.L. Song, C.N. Cao, and H.C. Lin, Corros. Sci., 36 (1994) 165-169.

[26] G. Song, Corros. Sci., 47 (2005) 1953-1987.

[27] C.-O.A. Olsson and D. Landolt, Electrochim. Acta, 48 (2003) 1093-1104.

[28] N. Padhy, R. Paul, U.K. Mudali, and B. Raj, Appl. Surf. Sci., 257 (2011) 5088-5097.

[29] M. Pourbaix, Iron, in: M. Pourbaix (Ed.), Atlas of electrochemical equilibria in aqueous 
solutions, NACE International, 1974, pp. 307-321.

[30] A. Samuni and S. Goldstein, J. Phys. Chem. A, 115 (2011) 3022-3028.

[31] T.R. Oliver and W.A. Waters, J. Chem. Soc. B, (1971) 677-681.

[32] S. Shackleford, Development of an EQCM based sensor for metal ions. 114-116. 2002. University of Central Lancashire. http://ethos.bl.uk/OrderDetails.do?uin=uk.bl.ethos.272808

[33] B. Gwinner, M. Auroy, D. Mas, A. Saint-Jevin, and S. Pasquier-Tilliette, J. Nucl. Mater., 428 (2012) 110-116.

[34] D.N. Hess, L. Rice, B. Willis, E.S. Snavely, and W.E. Clark, Corrosion of stainless steel in acidic nitrate waste solutions from processing stainless steel reactor fuels. ORNL-3474, 1-35. 1963. USA, Oak Ridge National Laboratory.

[35] C. Kato, F. Ueno, M. Yamamoto, Y. Ban, G. Uchiyama, Y. Nojima, and S. Fujine, ECS Trans., 53 (2013) 45-55.

[36] G. Le Gurun, C. Boxall, and R.J. Taylor, Modelling the photocatalytic reduction of actinide and lanthanide ions: A study by photopotentiometry, ECS Meeting Abstracts: 207th Meeting of the Electrochemical Society, Quebec City, Canada, 2005. 


\section{Figure Captions}

Figure 1. Linear sweep voltammograms (a and c) and polarisation curves (b and

d) for SS304L and SS316L in 5\% wt. $\mathrm{HNO}_{3}$ and AHA concentrations from 0.1 to $0.5 \mathrm{~mol} \mathrm{dm}^{-3}$.

Figure 2. Linear sweep voltammogram (a) and simultaneously recorded voltamassogram (b) for 5\% wt. $\mathrm{HNO}_{3}$ and $0.5 \mathrm{~mol} \mathrm{dm}{ }^{-3}$ AHA on SS2343 piezoelectrodes.

Figure 3. 3000x SEM backscatter images and measured maximum surface roughness $\left(\mathrm{R}_{\mathrm{z}}\right)$ and average surface roughness $\left(\mathrm{R}_{\mathrm{a}}\right)$ values of SS2343 piezoelectrodes. (a) Untreated crystal, (b) $5 \%$ wt. $\mathrm{HNO}_{3}$, (c) 5\% wt. $\mathrm{HNO}_{3}+0.5$ mol dm ${ }^{-3}$ AHA.

(a)

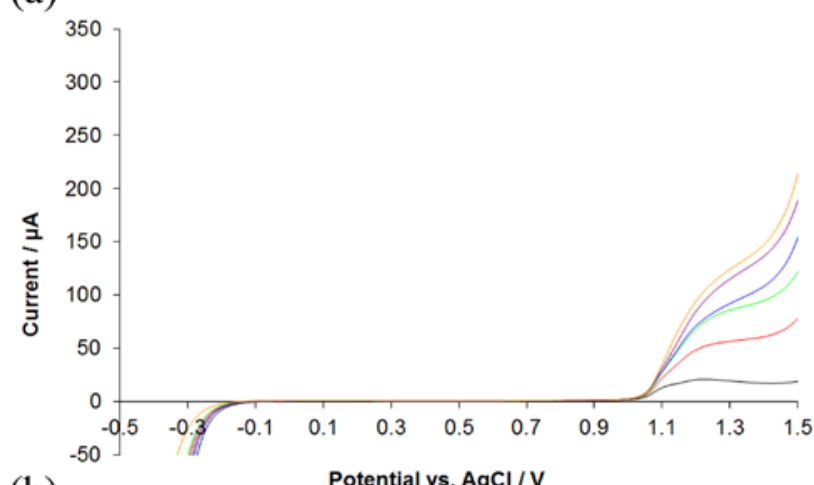

(b)

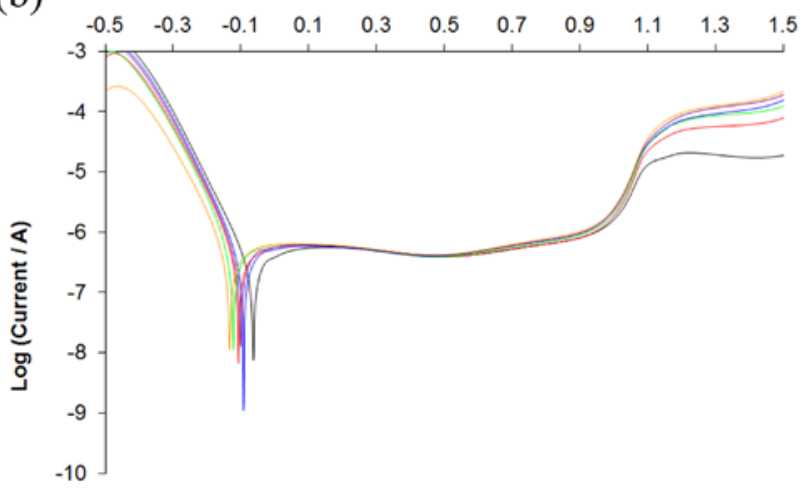

(c)

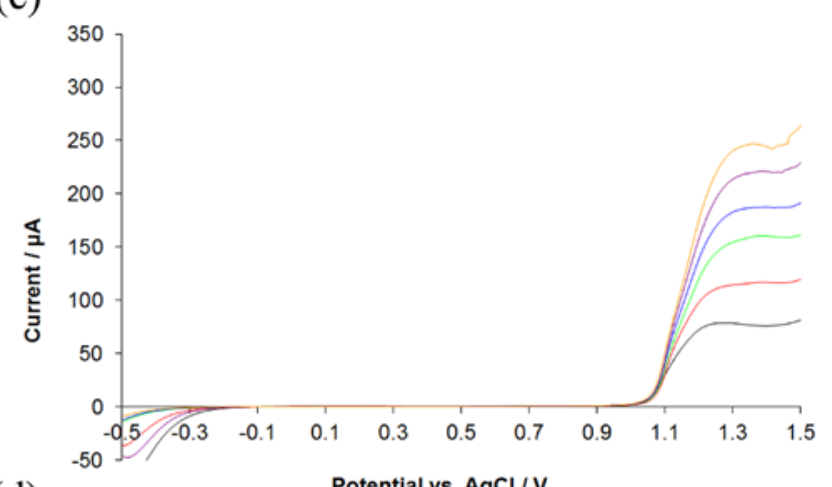

(d)

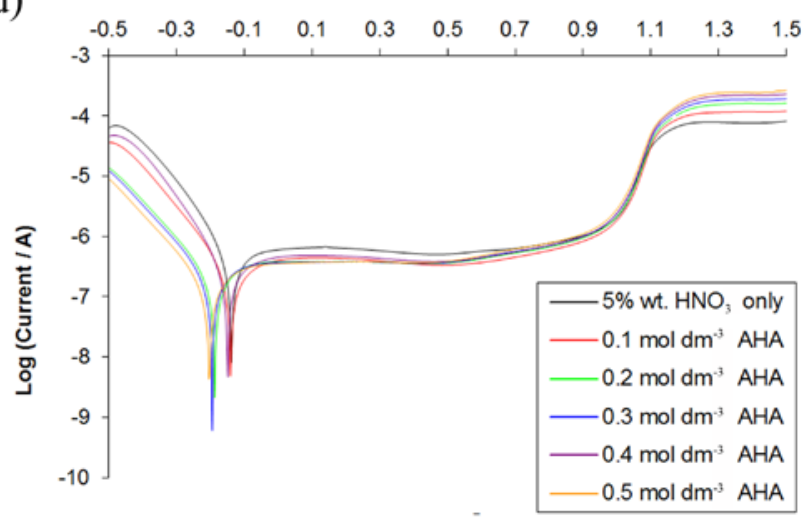

FIGURE 1 


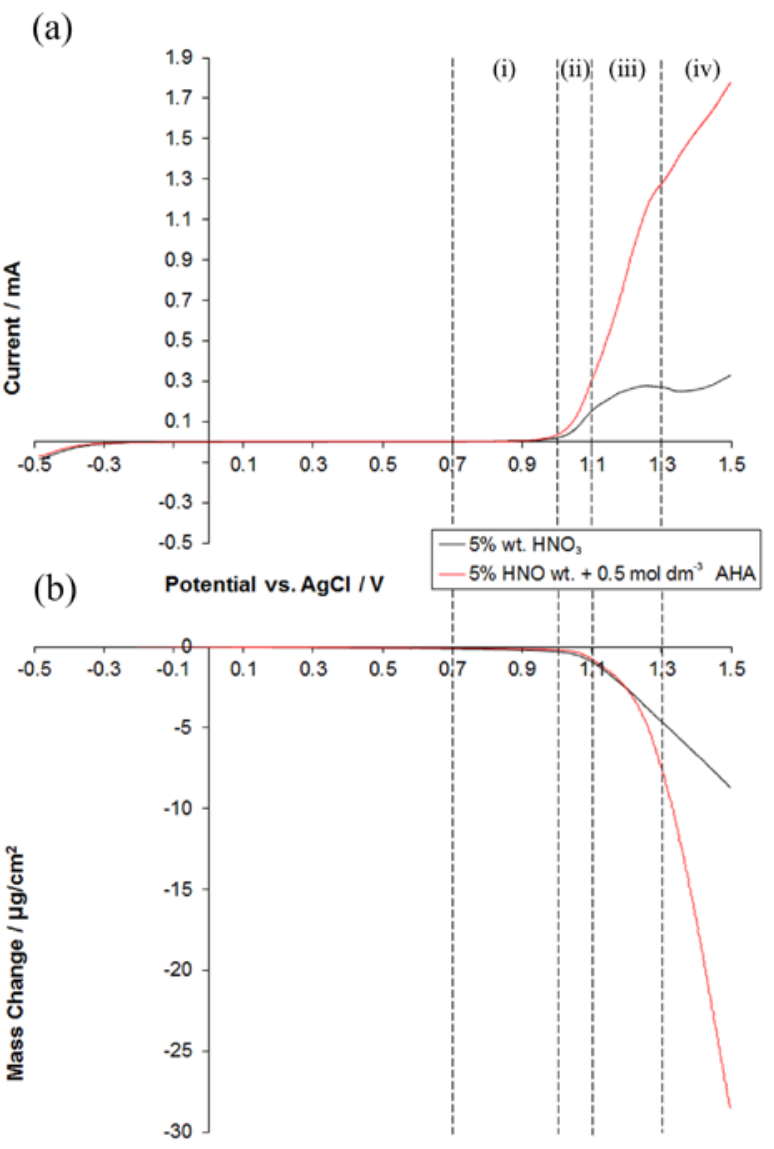

FIGURE 2
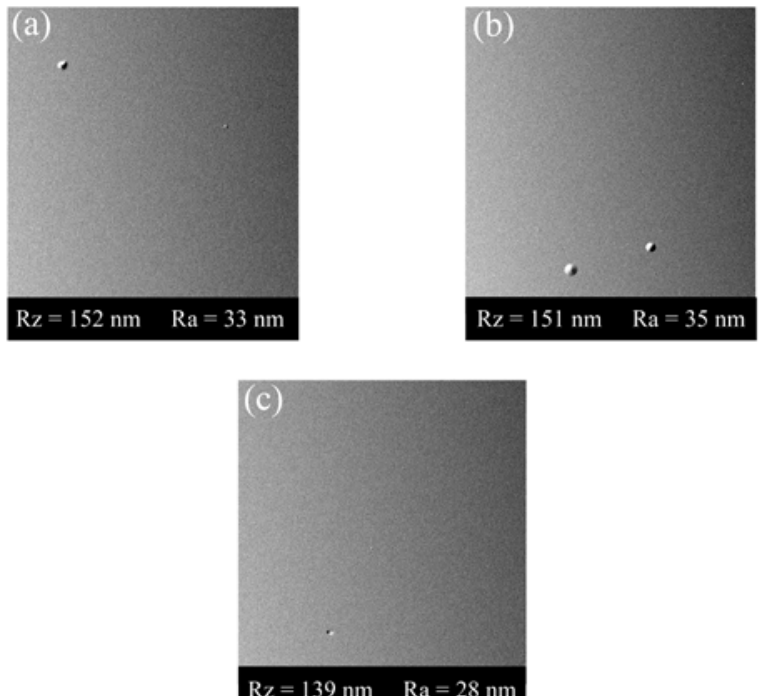

FIGURE 3 